\title{
MODIFIKASI MESIN PENANAM BIBIT PADI MANUAL DENGAN TRANSMISI RANTAI PENGGERAK MOTOR BENSIN 1,8 HP
}

\author{
Rofarsyam \\ Jurusan Teknik Mesin, Politeknik Negeri Semarang \\ Jl. Prof. Soedarto, SH, Tembalang, Semarang 50275 \\ E-mail:
}

\begin{abstract}
Abstrak
Mesin penanam bibit padi manual dengan penggerak tenaga manusia melalui transmisi engkol, dipandang masih belum menghasilkan fungsi yang diharapkan. Modifikasi dilakukan guna efisensi dan ekonomis, dengan pemberian penggerak motor bensin 1,8 HP dan setting link garpu serta pengaturan putaran motor, menghasilkan penanaman padi sesuai spesifikasi menanam padi pada jarak tanam 250 mm. Mesin hasil modifikasi ini berkapaistas 60 tancap setiap menit pada luas lahan $8 \mathrm{~m}^{2}$.
\end{abstract}

Kata Kunci : "mesin penanam bibit”, “motor bensin”, "bibit padi”

\section{Pendahuluan}

Penanaman bibit padi dengan cara tradisional langsung menancapkan bibit pada lahan menggunakan tangan lihat Gambar 2, dengan kapasitas 120 tancap setiap menit pada luas lahan $8 \mathrm{~m}^{2}$, dengan jarak tanam bervariasi antara 200 - 300 mm (anonim Diperta Kota Semarang 2013). Sedangkan mesin milik petani lihat Gambar 1, tidak dapat berfungsi sesuai yang diharapkan (Abuhasan 2015). Untuk mesin produksi Kubota Gambar 3 tergolong besar yang tidak terjangkau oleh petani, berkapasitas 360 tancap setiap menit pada luas lahan $4 \mathrm{~m}^{2}$, dengan jarak tanam $250 \mathrm{~mm}$ (anonim P Kubota 2012). Berdasarkan hal tersebut dipandang perlu rancangbangun modifikasi mesin penanam bibit padi manual milik petani tersebut, dengan tujuan efisien dan ekonomis, dengan penambahan penggerak motor bensin 1,8 HP dan penyetingan link garpu serta pengaturan putaran motor, agar kecepatan penanaman konstan. Kapasitas mesin hasil rancanganbangun mencapai 60 tancap setiap menit pada luas lahan $8 \mathrm{~m}^{2}$ dengan jarak tanam yang lazim yaitu $250 \mathrm{~mm}$.

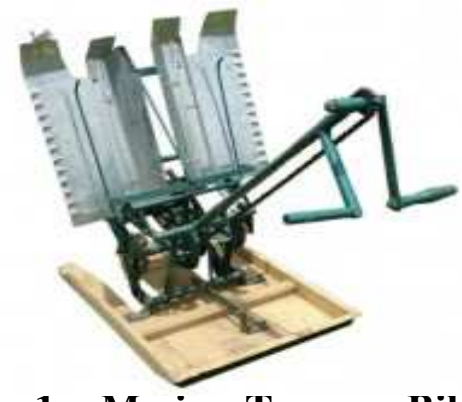

Gambar 1. Mesin Tanam Bibit Padi Manual Transmisi Engkol

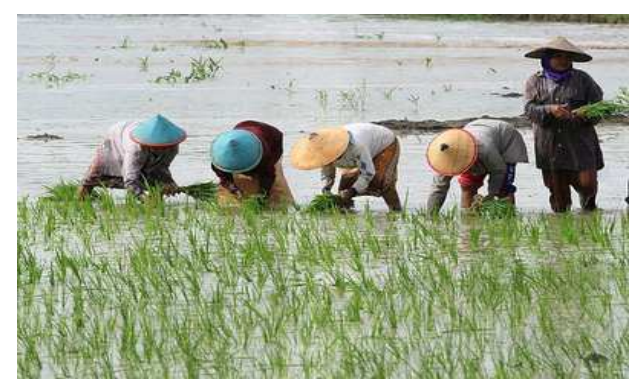

Gambar 2. Tanam Bibit padi Tradisional

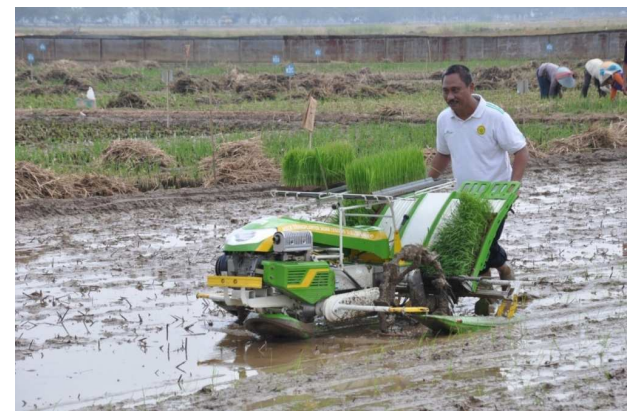

Gambar 3. Mesin Kubota. Tanam Bibit Padi Produksi

Berat $160 \mathrm{~kg}$, Daya 4.3 HP, Kapasitas : 30 menit /10000 tancap (Tahun 2013) 
2. Metode Perancangan dan Pembuatan Mesin

1). Mempelajari kekurangan mesin penanam bibit padi manual milik kelompok tani yang tidak dapat berfungsi sesuai yang diharap. Hasil analisis mesin manual tersebut menghasilkan kesimpulan umum adalah : setting link garpu tidak balance, putaran dan kecepatan tidak konstan.

2). Kemudian Langkah selanjutnya memodifikasi dan perbaikan sistem transmisi dan tenaga penggeraknya, agar mesin dapat berfungsi secara maksimal.

3). Desain mesin. Langkah yang dilakukan yaitu mengadopsi mekanisme mesin tanan bibit padi milik Kubota.

4). Pembuatan mesin. Dengan menambahankan motor bensin 1,8 HP sebgai penggerak, kemudian pengaturan link garpu sesuai jarak tanam. Kemudian pengaturan putaran motor agar kecepatan konstan serta diberi seluncur pada landasan bawah. Seluncur berfungsi untuk slip melancarkan jalannya mesin.

5). Batasan masalah dalam pembuatan mesin tersebut adalah :

- Mesin ini hanya digunakan untuk padi yang sudah disemai, bibit padi umur 15 hari sesuai lazimnya

- Mesin digunakan pada Lahan siap tanam dengan kriteria sesuai lazimnya dan tinggi air maksimal 5 $\mathrm{mm}$ dan paling rendah $4 \mathrm{~mm}$ dari permukaan tanah

- Mesin menggunakan penggerak motor bensin dengan transmisi rantai tanpa kopling

- Mudah dioperasikan oleh operator

- Mesin mampu menancap dibandingkan mesin manual sebelumnya dan jarak tanam sesuai standar yang lazim yaitu $250 \mathrm{~mm}$

- Mesin langsung bergerak ketika motor dihidupkan tanpa menggunakan kopling

- Mesin yang dihasilkan seperti yang ditujnukkan pada Gambar 4.
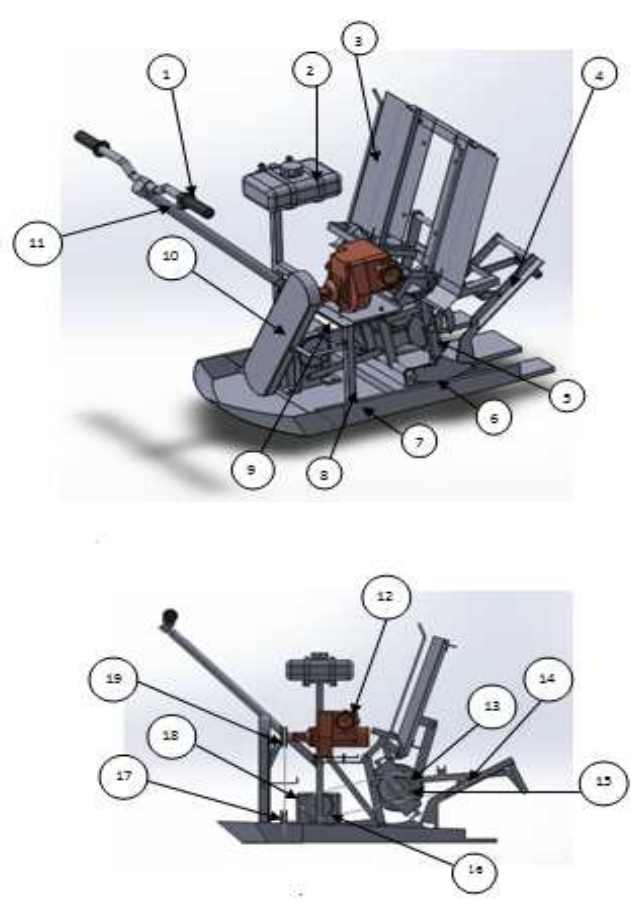

Gambar 4. Mesin Tanam Bibit Padi Hasil Rancangbangun

Keterangan nomor gambar :

1. Handle

2. Tangki Bensin

3. Tempat Bibit Padi

4. Fork Link

5. Link Garpu

6. Plat penyangga bibit Padi

7. Papan Selancar

8. Rangka

9. Dudukan Tempat Bahan Bakar

10. Tutup Puli

11. Stoping

12. Motor bensin

13. Gear V

14. Gear VI

15. Gear IV

16. Gear III

17. Puli II

18. Reduser

19. Puli I

Motor bensin menggerakan reducer dan diteruskan garpu link menggunakan rantai. Ketika link garpu berputar, forlink padi juga ikut berputar karena transmisinya dihubungkan sama menggunakan rantai. 
- Pengoperasian alat :

1) Mempersiapkan bibit padi dan lahan sawah untuk media penanam padi

2) Pasang bibit padi pada penyangga bibit padi

3) Isi bensin campuran pada tangki bensin

4) Nyalakan motor bensin

5) Tarik tuas mesin penanam padi

6) Matikan mesin dengan tombol off ketika akan membelok ke baris selanjutnya

7) Ketika bensin dan bibit padi habis matikan mesin dan lakukan pengisian ulang

8) Lakukan tahap di atas sampai lahan tertanam bibit padi seluruhnya

\section{Pengujian}

Mesin tanam bibit padi yang dihasilkan seperti yang ditunjukkan pada Gambar 4 . Hasil pengujian mesin dilakukan pada lahan milik instansi Pertanian yang ada di Boja Kendal. Adapun hasilnya seperti pada tabel 1.

Tabel 2. Data kecacatan produk dalam lima hari kerja

\begin{tabular}{c|c|c|c|c}
\hline No & $\begin{array}{c}\text { Jarak } \\
\text { Lahan } \\
(\mathrm{m})\end{array}$ & $\begin{array}{c}\text { Jarak Tanam } \\
(\mathrm{mm})\end{array}$ & $\begin{array}{c}\text { Waktu } \\
(\mathrm{det})\end{array}$ & $\begin{array}{c}\text { Jumlah } \\
\text { Tancap } \\
\text { (buah) }\end{array}$ \\
\hline 1 & 2,8 & 250 & 8 & 16 \\
\hline 2 & 2,8 & 250 & 9 & 18 \\
\hline 3 & 2,8 & 250 & 10 & 20 \\
\hline 4 & 2,8 & 250 & 11 & 20 \\
\hline 5 & 2,8 & 250 & 12 & 21 \\
\hline 6 & 2,8 & 250 & 13 & 21 \\
\hline 7 & 2,8 & 250 & 14 & 24 \\
\hline 8 & 2,8 & 250 & 8 & 17 \\
\hline 9 & 2,8 & 250 & 9 & 19 \\
\hline 10 & 2,8 & 250 & 10 & 20 \\
\hline 11 & 2,8 & 250 & 11 & 21 \\
\hline 12 & 2,8 & 250 & 12 & 21 \\
\hline 13 & 2,8 & 250 & 13 & 24 \\
\hline 14 & 2,8 & 250 & 14 & 24 \\
\hline 15 & 2,8 & 250 & 11 & 20 \\
\hline $\mathrm{XR}$ & 2,8 & 250 & 11 & 20,4 \\
\hline
\end{tabular}

\section{Hasil dan Pembahasan}

1. Perhitungan $\mathrm{K}$ apasitas

Perhitungan kapasitas (Q) menggunakan rumus $Q=\frac{\text { Jumlah Tancap }}{\text { waktu }}$ (Abuhasan 2015). dan beberapa variabel direncanakan sebagai berikut :sekali tancap $=1$ detik, Jarak tanam kesamping $=250 \mathrm{~mm}$, Jarak tanam kebelakang $=250 \mathrm{~mm}$, Panjang sawah $=8200 \mathrm{~mm}$, dan lebar sawah $=8200$ $\mathrm{mm}$. Sketsa sawah seperti yang ditunjukkan pada Gambar 1.

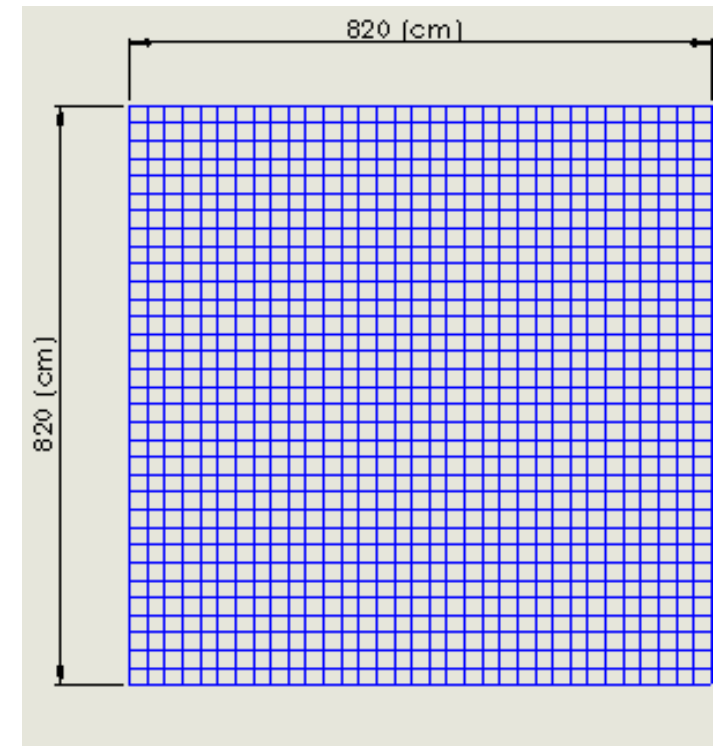

\section{Gambar 5. Sektsa lahan}

$\mathrm{Q}=\frac{\text { Jumlah Tancap }}{\text { waktu }}=\frac{\mathrm{Jlt}}{\mathrm{t}}$

$\mathrm{Q}=$ Kapasitast, $\mathrm{t}=$ waktu menit

Menentukan banyaknya tiap tancapan kearah belakang (Jlt-b)

$$
\begin{aligned}
\text { Jlt- } \mathrm{b} & =\frac{\text { panjang sawah }}{\text { jarak tanam }}=\frac{8200 \mathrm{~mm}}{250 \mathrm{~mm}} \\
& =32 \text { [tancap] }
\end{aligned}
$$

Menentukanbanyaknyatiaptancapankearahsa mping (Jlt-s)

$$
\begin{aligned}
\text { Jlt-s } & =\frac{\text { panjang sawah }}{\text { jarak tanam }}=\frac{8200 \mathrm{~mm}}{250 \mathrm{~mm}} \\
& =32 \text { tancap }
\end{aligned}
$$


Karenajumlahlinkada2,jadi $=32: 2=16$ [tancap]

Menentukanjumlahtancap (Jlt):

$\mathrm{Jlt}=32$ [tancap]x16[tancap] $=512$ [tancap]

$\mathrm{Q}=512$ Tancapan dapat menyelesaikan dengan waktu 512 [detik]

$\mathrm{Q}=\frac{512 \text { tancap }}{512 \text { detik }}=\frac{60 \text { tancap }}{\text { menit }}$

\section{Perhitungan Daya Penggerak}

Dari pengujian yang dilakukan disawah mijen dengan menggunakan alat ukur dynamometer dapat di rata- rata gaya tancap (F) sebesar0.75 [N]. Daya dihitung menggunakan rumus : $\mathrm{P}=\mathrm{T} . \omega$. Besar daya penggerak adalah jumlah total dari beberapa daya pada tingkatan transmisi yang meliputi :

a. $\mathrm{P}=$ Daya untuk menggerakan poros [watt]

$\mathrm{T}=$ Torsi $[\mathrm{Nm}]=$ F.r $=0,75[\mathrm{~N}] \cdot 250$ $[\mathrm{mm}]=187,5[\mathrm{Nmm}]$

$\omega=$ Kecepatan sudut $\quad[\mathrm{rad} / \mathrm{s}]=$

$\frac{2 \pi \mathrm{n}}{60} \quad[\mathrm{rad} / \mathrm{s}],-\mathrm{n}=$ putaran rantai motor[rpm], dari perbandingan transmisi didapat $\mathrm{n}=60,86[\mathrm{rpm}] \approx 60 \quad[\mathrm{rpm}]$. Maka $\omega=$ Kecepatan sudut $\quad[\mathrm{rad} / \mathrm{s}]$ $=6,28[\mathrm{rad} / \mathrm{s}]$.

b. Daya Pada Forklink $\mathrm{P}=\mathrm{T} . \omega=0,187$ $[\mathrm{Nm}]$. $6.28[\mathrm{rad} / \mathrm{s}]=1,174$ [watt $]=$ 0.001575 [HP]. Daya rencana untuk keperluan daya rencana, maka daya dikalikan factor koreksi ( $\left.f_{c}\right) \quad=1,2$ $\mathrm{Pd}$

= fc. P ( Sularso,2008:7 ). Sehingga daya rencana $\mathrm{Pd}=1,2 \cdot 1,174$ [Watt] $=1,408$ $[$ Watt $]=0,0018[\mathrm{HP}]$. Jadi daya rencana untuk memutar Forklink sebesar 0,0018 [HP]

c. Daya Transmisi Pada Poros Utama

Diketahui sesuai yang direncanakan beberapa variaØle berikut :Massa jenis poros $=7850\left[\mathrm{~kg} / \mathrm{m}^{3}\right]$. Percepatan gravitasi $(\mathrm{g})=9,81\left[\mathrm{~m} / \mathrm{s}^{2}\right]$, Putaran poros $\left(N_{2}\right)=$ $30[\mathrm{rpm}]$, Diameter poros $(\mathrm{d}) \quad=19$ $[\mathrm{mm}]=0,019[\mathrm{~m}]$, Panjang poros $(\ell)=335$ $[\mathrm{mm}]=0,335[\mathrm{~m}]$, Faktor Koreksi (fc) $=1,2$. Volume poros dihitung $\mathrm{V}=\frac{\pi}{4}\left(\mathrm{~d}^{2} \cdot \mathrm{L}\right)=\frac{\pi}{4}\left(0,019^{2} \cdot 0,335\right)=9,498$ $\mathrm{x} 10^{-5}\left[\mathrm{~m}^{3}\right]$. Massa poros $\mathrm{m}=\rho . \mathrm{V}=7850$ $\left[\mathrm{kg} / \mathrm{m}^{3}\right] .9,498 \times 10^{-5}\left[\mathrm{~m}^{3}\right]=0,74[\mathrm{~kg}]$. Kecepatan linier poros $\mathrm{v}=\frac{\pi \mathrm{d} \mathrm{n}_{2}}{60}=0,029$ $[\mathrm{m} / \mathrm{s}]$.

Daya pada poros utama $\mathrm{P}=\mathrm{w} \cdot \mathrm{v}=(\mathrm{m} . \mathrm{g})$ $\cdot \mathrm{v}=0,74 \cdot 9,81 \cdot 0,029=0,21$ [watt] $=$ 0,0002 [HP].

Jadi daya rencana pada poros sebesar : $\mathrm{P}$ $=0,21[$ Watt $] \cdot 1,2=0,252[$ Watt $]=$ 0,0003 [HP]

d. Daya untuk Memutar Puli Reducer Massa jenis Aluminium $=2700\left[\mathrm{~kg} / \mathrm{m}^{3}\right]$, Percepatan gravitasi $(\mathrm{g})=9,81\left[\mathrm{~m} / \mathrm{s}^{2}\right]$ Putaran puli $\left(N_{2}\right)=4200[\mathrm{rpm}]$, Diameter luar puli $(\mathrm{dc})=100[\mathrm{~mm}]=0,1[\mathrm{~m}]$, Faktor Koreksi $\left(f_{c}\right)=1,2$, Lebar puli $b=2$ f, dimana $\mathrm{f}=1 / 2$ lebar puli $[\mathrm{mm}]=10[\mathrm{~mm}]$, leber puli $=2.10[\mathrm{~mm}]=20[\mathrm{~mm}]$. Volume puli (V) $v=\frac{\pi}{4} \mathrm{~d}^{2}, \mathrm{~b}=1,57 \times 10^{-4}$ $\left[\mathrm{m}^{3}\right]$, Massa puli $(\mathrm{m})=0,4239[\mathrm{~kg}]$, Kecepatan linier puli $(\mathrm{vl})==21,99[\mathrm{~m} / \mathrm{s}]$ Daya untuk memutar puli $\mathrm{P}=(\mathrm{m} . \mathrm{g}) . \mathrm{v}=($ $\left.0,4239[\mathrm{~kg}] \cdot 9,81\left[\mathrm{~m} / \mathrm{s}^{2}\right]\right)$. 21,99 [m/s] = 91,44[Watt] $=0,122$ [HP]

Jadi daya rencana pada puli $\mathrm{P}=91,44$ [Watt]. 1,2 =109,728 [Watt] $=0,147$ [HP]

e. Daya untuk Memutar rantai 1

Perhitungan daya pada rantai1. Rantai1 berada pada poros utama yang diteruskan dari reducer. Adapun variabelnya : 
Percepatan gravitasi $(\mathrm{g})=9,81\left[\mathrm{~m} / \mathrm{s}^{2}\right]$, Massa rantai $=0,3[\mathrm{~kg}]$, Putaran rantai pada poros utama $(\mathrm{n})=30[\mathrm{rpm}]$ didapat dengan rumus perbandingan putaran $\frac{\mathrm{n}_{1}}{\mathrm{n}_{2}}=\frac{\mathrm{d}_{2}}{\mathrm{~d}_{1}}$ (Khurmi, 2011), diameter rantai $(\mathrm{d})=0,115[\mathrm{~m}]$, Faktor Koreksi $\left(\mathrm{f}_{\mathrm{c}}\right)=1,2$. Kecepatan linier rantai $(\mathrm{v})=0,180[\mathrm{~m} / \mathrm{s}]$. Daya untuk memutar rantai $1 \mathrm{P}=(\mathrm{m} . \mathrm{g}) . \mathrm{v}$ $=\left(0,3[\mathrm{~kg}] \cdot 9,81\left[\mathrm{~m} / \mathrm{s}^{2}\right]\right) \cdot 0,180[\mathrm{~m} / \mathrm{s}]=$ $0,529[\mathrm{Watt}]=0,0007$ [HP]

Jadi daya rencana pada rantai $1 \mathrm{P}=0,529$ [Watt]. 1,2=0,634 [Watt] =0,0008 [HP]

f. Daya untuk Memutar rantai 2

Perhitungan daya pada rantai 2. Rantai2 berada pada poros Forklink yang diteruskan dari poros utama. Variabelnya : Percepatan gravitasi $(\mathrm{g})=$ $9,81\left[\mathrm{~m} / \mathrm{s}^{2}\right]$, Massa rantai $=0,2[\mathrm{~kg}]$, Putaran rantai pada poros forklink $(\mathrm{n})==$ $0,055[\mathrm{rpm}]$, Dameter rantai $(\mathrm{d})=60[\mathrm{~m}]$, Faktor Koreksi $\left(\mathrm{fc}_{\mathrm{c}}\right)=1,2$. Kecepatan linier rantai $(\mathrm{v})=0,172[\mathrm{~m} / \mathrm{s}]$

Daya untuk memutar rantai $2 \mathrm{P}=(\mathrm{m} . \mathrm{g}) . \mathrm{v}$ $=\left(0,2[\mathrm{~kg}] \cdot 9,81\left[\mathrm{~m} / \mathrm{s}^{2}\right]\right) \cdot 0,172 \mathrm{~m} / \mathrm{s}=$ $0,337$ [Watt $]=0,0004$ [HP]

Jadi, daya rencana pada rantai 2 sebesar $=$ 0,4 [Watt]. 1,2 = 0,0005 [HP]

g. Daya yang dibutuhkan ;

Daya $=$ Perhitungan daya pada Forklink + Daya untuk memutar poros utama + Daya untuk memutar puli pada reducer + Daya untuk memutar rantai 1 + Daya untuk memutar rantai 2

Daya $=0,0018[\mathrm{HP}]+0,0003[\mathrm{HP}]+$ $0,147[\mathrm{HP}]+0,0008[\mathrm{HP}]+0,0005[\mathrm{HP}]=$ 0,1504 [HP], sehingga motor penggerak yang digunakan adalah motor yang ada di pasaran, yaitu $\mathrm{P}=1,8[\mathrm{HP}]$
3. Analisis hubungan waktu dengan jumlah tancap

Tabel 1 menunjukkan waktu rata-rata 11 detik menghasilkan rata-rata 20 tancap dan pada perhitungan kapasitas direncanakan dan diasumsikan beberapa variabel berikut dan lihat sket luas lahan pada Gambar 5. Gambar 6 adalah grafik hubungn waktu dengan jumlah tancap.

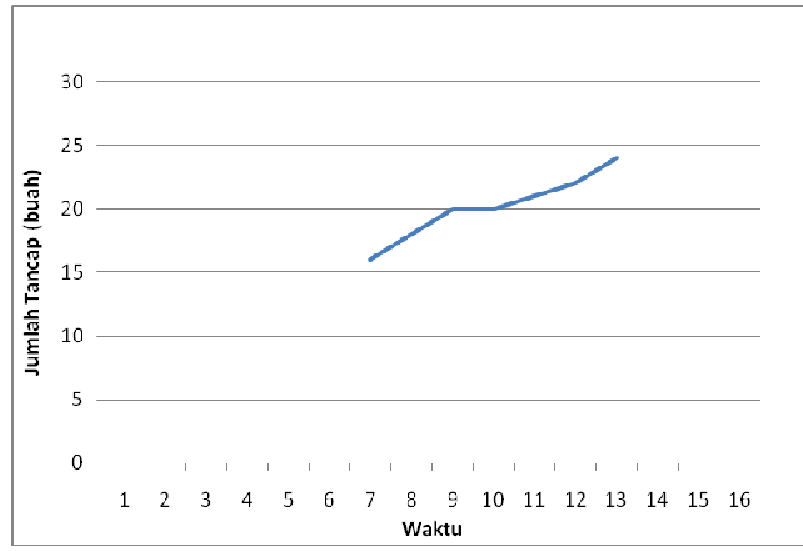

\section{Gambar 6. Jumlah tancap fungsi waktu}

Persamaan garis : $\mathrm{y}=\mathrm{a}+\mathrm{b} \mathrm{x}$

Nilai koefisien $a=\frac{\sum \mathrm{y} \cdot \sum \mathrm{x}^{2}-\sum \mathrm{x} \cdot \sum \mathrm{x} \cdot \mathrm{y}}{\mathrm{n} \sum \mathrm{x}^{2}-\left(\sum \mathrm{x}\right)^{2}}$

( Sugiyono. 2012)

$\mathrm{a}=8,025$

Nilai koefisien $\mathrm{b}=\frac{\mathrm{n} \sum \mathrm{x} \cdot \mathrm{y}-\sum \mathrm{x} \cdot \sum \mathrm{y}}{\mathrm{n} \sum \mathrm{x}^{2}-\left(\sum \mathrm{x}\right)^{2}}$

$\mathrm{b}=1,125$

sehingga persamaan garisnya adalah ; Jlt = $8,025+1.125 \mathrm{t}$

Koefisien korelasi antara $(\mathrm{Jlt}$ dengan $\mathrm{t}): \mathrm{r}=$ $\frac{\sum \mathrm{x} \cdot \mathrm{y}}{\sqrt{\sum \mathrm{x}^{2} \cdot \sqrt{\sum \mathrm{y}^{2}}}}$

Konsta a menggunakan rumus : $\mathrm{a}=\mathrm{X}-\overline{\mathrm{X}}$ Konsta $\mathrm{b}$ menggunakan rumus : $\mathrm{b}=\mathrm{Y}-\overline{\mathrm{Y}}$ Sehingga $r=0,9436$ 
Persentasi hubungan adalah $\mathrm{KP}=(0,9436)^{2}$. $100 \%=89 \%$

Hubugan waktu dengan jumlah tancap sangat kuat, semakin banyak waktu yang digunakan maka semakin banyak pula jumlah yang tertancap.

\section{Kesimpulan dan Saran}

Hasil keseluruhan dari modifikasi mesin penanam bibit padi manual dengan penggerak motor bensin $1.8 \mathrm{HP}$ memiliki spesifikasi :

- Penggerak motor bensin 1.8 HP

- Dimensi mesin 1156 x 526 x 763 [mm]

- Kapasitas 60 tancap / menit dengan luas lahan $8 \mathrm{~m}^{2}$

- Disarankan perbaikan ulang transmisi untuk mencapai putaran yang sesuai keinginan

- Disarankan menggunakan kopling dan pengaturan putaran

\section{Daftar Pustaka}

- Anonim. 2012 . Katalog Mesin Pertanian Produksi PT Kubota, Semarang PT Kubota

- Anonim. 2013. Budidaya Pertanian Menuju Swadaya Pangan.. Semarang. Diperta Kota Semarang.

- Abuhasan. 2015. Modifikasi Mesin Penanam Bibit Padi Manual Dengan Penggerak otor Bensin 1,9 HP. Semarang. Teknik Mesin Politeknik Negeri Semarang

Khurmi, R.S \& J.K. Gupta. 2011. A Text Book Of Machine Design. New Delhi. Eurasia Publishing House (Pvt) Ltd

- Prof. DR. Sugiyono. 2012. Statistika untuk Penelitian. Bandung. CV Alfabeta Bandung

- Sularso, Kiyokatso Suga.2012. Dasar Perencanaan dan Pemilihan Elemen Mesin. Jakarta. PT. Pradnya Paramita 